\title{
Review
}

Neonatology

Neonatology 2014;105:14-24

DOI: $\underline{10.1159 / 000354944}$
Received: June 4, 2013

Accepted after revision: August 6, 2013

Published online: November 2, 2013

\section{Research on Neonatal Microbiomes: What Neonatologists Need to Know}

\author{
Michael P. Sherman ${ }^{a} \quad$ John Minnerly ${ }^{b}$ William Curtiss ${ }^{b}$ Shaukat Rangwala ${ }^{b}$ \\ Scott T. Kelley ${ }^{\mathrm{c}}$ \\ ${ }^{a}$ Department of Child Health, University of Missouri, Columbia, Mo., ${ }^{b}$ MOgene, St. Louis, Mo., and \\ 'Department of Biology, San Diego State University, San Diego, Calif., USA
}

\section{Key Words}

Biodiversity · Bioinformatics · Genome analyzers .

Pyrosequencing $\cdot$ Taxonomy

\begin{abstract}
The aim of this article is to educate neonatal caregivers about metagenomics. This scientific field uses novel and ever changing molecular methods to identify how infants become colonized with microbes after birth. Publications using metagenomics appear infrequently in the neonatal literature because clinicians are unaccustomed to the analytical techniques, data interpretation, and illustration of the results. This review covers those areas. After a brief introduction of neonatal citations forthcoming from metagenomic studies, the following topics are covered: (1) the history of metagenomics, (2) a description of current and emerging instruments used to define microbial populations in human organs, and (3) how extensive databases generated by genome analyzers are examined and presented to readers. Clinicians may feel like they are learning a new language; however, they will appreciate this task is essential to understanding and practicing neonatal medicine in the future.
\end{abstract}

(c) 2013 S. Karger AG, Basel

\section{Introduction}

At birth, neonatal organs are either sterile or have low numbers of bacteria, but by adulthood, there are between 10 and 100 trillion microbes residing in the human body. Microbial environments in neonates and adults of interest include the skin, nose and oropharynx, the lower respiratory tract, the gastrointestinal tract with its regional differences, and the urogenital tract with special interest in the vagina [1]. Of these habitats, microbes living in the small and large intestine of prematurely born infants have received the most attention. Fecal specimens showing reduced gut-related bacterial diversity and the presence of potential pathogens are associated with late-onset neonatal sepsis [2]. Moreover, a shift in the fecal microbiota to a predominance of the phylum Proteobacteria and a reduction in the phylum Firmicutes has been seen $72 \mathrm{~h}$ before the onset of necrotizing enterocolitis [3]. Understanding how microbial diversity in infants relates to neonatal infections is an important aspect of this research.

Presently, it is appreciated that the composition of intestinal microbiota is influenced by an infant's genetic background [4, 5], vaginal or caesarean delivery [6], residence at home versus in the hospital [7-9], the adminis-

\section{KARGER}

E-Mail karger@karger.com

www.karger.com/neo (c) 2013 S. Karger AG, Base

$1661-7800 / 14 / 1051-0014 \$ 39.50 / 0$
Prof. Michael P. Sherman

Suite 206, Division of Neonatology

Women's and Children's Hospital

404 Keene Street, Columbia, MO 65201 (USA)

E-Mail ShermanMP@ health.missouri.edu 
tration of antibiotics $[10,11]$, and a diet consisting of parenteral nutrition, breast milk, formula, fortifiers or a combination of those nutrients $[12,13]$. The dynamic ecosystem developing in the gut plays major roles in nutritional, metabolic, physiologic, and immunologic processes [14-16]. Current concepts suggest that the development of intestinal microbiota have associations with the pathogenesis of obesity $[17,18]$, diabetes $[19,20]$, and allergic disease [21,22]. Given the effects of antibiotics on the composition of microbes in the neonatal intestine and their effects on future health, proper use of these agents has vast significance.

Bacterial classification or taxonomy has been the focus in studying neonatal environments, but the field is rapidly moving towards comprehending functional relationships among microbes and between microbes and their host [23]. Future research must integrate data about the microbiota with (a) the complete set of RNA transcripts produced by environmental genomes at study sites (transcriptome), (b) the complete array of structural and functional proteins expressed by genomes in a habitat (proteome), and (c) the full complement of small molecular metabolites identified in a biological sample from a host and subject-related microbes (metabolome) [24]. Only when the classification of bacteria in habitats is integrated with their effects on cellular function will the field of metagenomics influence neonatal therapeutics.

The remainder of this article discusses metagenomics and because certain words may be unfamiliar, the Appendix has a glossary of terms that are employed in this review.

\section{A Historical Perspective of Metagenomics}

The ensuing points recount the switch from culturebased microbiology to culture-independent DNA sequencing to identify microbes in the body.

- Over 125 years ago, Koch and colleagues invented culture-based methods for bacterial isolation [25]. Laboratory medicine still uses these techniques to diagnose infection, but molecular systems are supplanting some of those procedures [26].

- Woese and Fox [27] used the small subunit of ribosomal nucleic acid (16S rRNA) of microorganisms and discovered a new domain, the Archaea. In establishing phylogenetics [28], Professor Woese gave scientists a roadmap to a new discipline.

- Pace et al. [29] proposed cloning DNA directly from environmental samples. This task was accomplished and it took microbiology further into the molecular era [30].

- While this field initially started with cloning of environmental DNA, it was followed by screening for gene expression and function in soil microbes [31]. Shotgun sequencing of environmental DNA showed the use of this approach in more robust projects [32,33].

- Crucial to studying microbes in human habitats, Nobel Laureates Fred Sanger and Walter Gilbert had previously invented methods of DNA sequencing [34-36]. In the next decade, Nobel Laureate Kary Mullis described the polymerase chain reaction (PCR) to amplify miniscule amounts of DNA in a specimen [37]. These methods were absolutely required to advance clinical and investigative medicine, but their laborious nature initiated a search for automated DNA analyses.

- In 1996, a novel method called pyrosequencing was reported [38]. Pyrosequencing was the birth of the 'next or 2nd generation' of DNA analytical methods and was based on detection of pyrophosphate release when a nucleotide is incorporated into DNA [39]. Conversely, Sanger sequencing is based on chain termination with dideoxynucleotides [36]. Commercial instrumentation using pyrosequencing to analyze DNA became available in 2005, and this method is less time-consuming and more cost-effective [40].

- Two years after the pyrosequencing method was announced, Handelsman coined the term metagenome to describe cloning of the collective genomes and the biosynthetic machinery of soil microflora so their functions could be better appreciated [31]. Hence, an analytical way to study complex genomes in an environment came forth in the same timeframe as the concept of metagenomics.

\section{The Human Microbiome Project}

In 2001, Nobel Laureate Joshua Lederberg [41] devised the word 'microbiome' to describe the microbiota and their collective genomes as an ecologic community living in the human body. The collective bacteria and their genes in the intestine of infants is an example of a 'neonatal microbiome'. Relman and Falkow [42] also suggested in 2001 that a 'second human genome project' define the interactions between microbial commensals and pathogens and their hosts. This idea gained momentum and the Human Microbiome Project (HMP) was born in 2007 [43]. In the remainder of this review, the analytical 


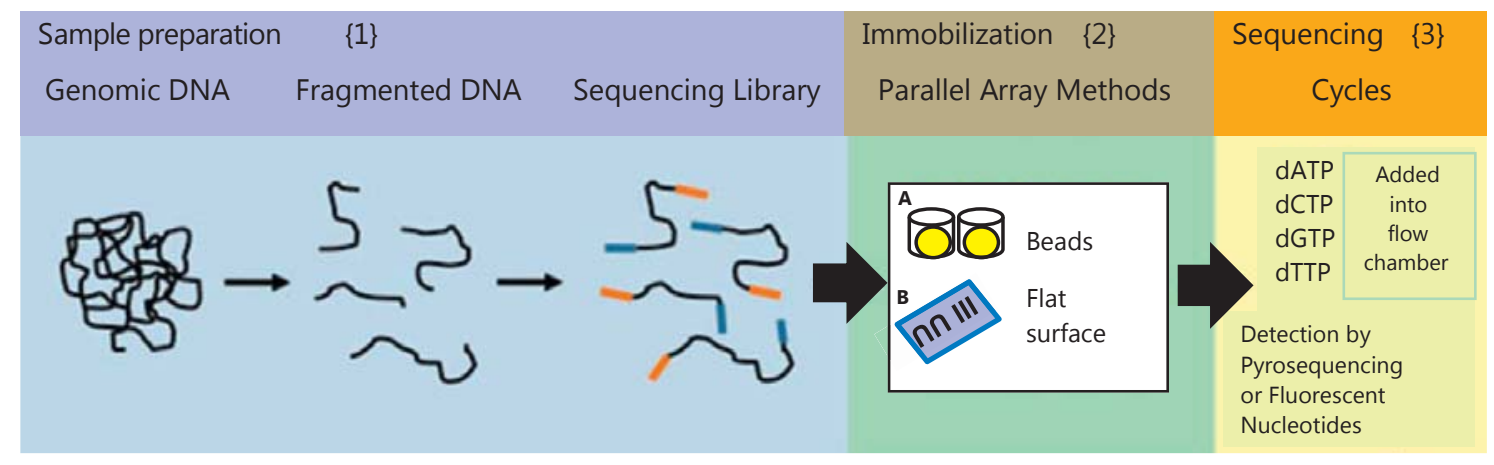

Fig. 1. The three steps associated with next generation sequencing. Step 1 depicts genomic DNA isolation from an environmental sample followed by DNA fragmentation and generation of the amplicon library. In step 2A, 454 Life Sciences system uses beads for amplification. In step 2B, the Illumina platform uses bridge amplification followed by cluster formation (depicted as $\cap \cap$ to \|\|$)$. During step 3 , sequencing occurs by addition of deoxynucleotide triphosphates (dNTPs) that are incorporated into single-stranded DNA (ssDNA), an event detected by emission of light or fluorescence.

systems commonly used to study neonatal microbiomes are explained. Thereafter, the bioinformatics used to correct errors that are inherent in the experimental methods that investigate microbiomes are summarized. Finally, how bioinformatics converts raw data to representations of an environmental microbiome in a scientific publication are depicted and described.

\section{Workflow Protocols Used in Studying a Neonatal Microbiome}

The term 'workflow' has two connotations in metagenomics. The first involves protocols used while performing genomic studies on different analytical instruments. These commercial instruments are also known as platforms. A second meaning for workflow is the application of computerized methods to obtain data from an analytical device. Workflow procedures depend on the instrument used for genomic analysis. The following automated platforms will be discussed.

Next or 2nd-Generation Sequencing Platforms and the Year Introduced

(a) 454 Life Sciences Analyzers: GS FLX+ Titanium \& GS Junior Systems; 2005.

(b) Illumina/Solexa Analyzers: Genome IIx, HiSeq and MiSeq Systems; 2006.

(c) Life Technologies Analyzers: Ion Torrent and Ion Proton Systems; 2011.

\section{3rd-Generation Platforms (Single-Molecule} Sequencing) and the Year Introduced

(a) Pacific Biosciences Sequencer: PacBio RS and SMRT Systems; 2011.

(b) Oxford Nanopore Technologies: 'Single-strand' \& 'Endonuclease' Systems; 2012.

Critically important to any protocol involving DNA analysis is the collection, the handling and the storage of samples, and quality assurance procedures must be applied [44-46]. New investigators to the field must be highly knowledgeable about the methods that yield optimal specimens for analyses. For example, the collection and storage of feces may be less detailed than that for studying intestinal tissue.

Figure 1 depicts the three major steps used during DNA analysis: preparation, immobilization, and sequencing. Immobilization is critical to 'Next Gen' technology because amplification of DNA is required for sufficient analytical material during sequencing. The Next Generation system used most often to study microbiota in neonatal environments is the 454 Life Sciences platform. For this reason, the methods describing the 454 system are more completely presented. The first to last step in 454 pyrosequencing are: (1) isolation of genomic DNA; (2) DNA fragments are generated [47]; (3) the ends of DNA fragments are repaired; (4) single-stranded DNA (ssDNA) fragments are used to generate an amplicon library (fig. 2a) [46, 48]; (5) the amplicon library is then pooled, cleaned, size-selected, and quantified; (6) ssDNA is then annealed to capture beads; (7) beads are emulsified in water-in-oil microreactors (one amplicon attached to
16

Neonatology 2014;105:14-24 DOI: $10.1159 / 000354944$
Sherman/Minnerly/Curtiss/Rangwala/ Kelley 


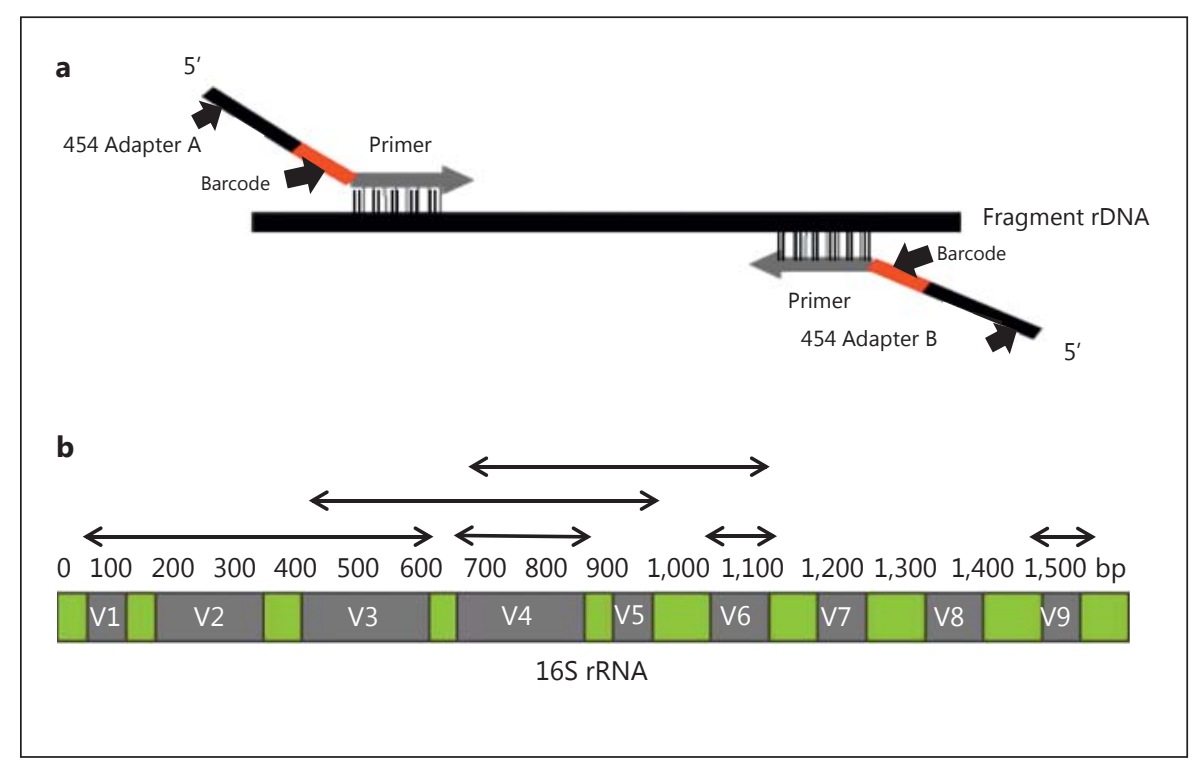

Fig. 2. Identification of bacteria during 454 Life Sciences sequencing. a A fragment isolated from genomic DNA that is used in 454 pyrosequencing. The fragment has a $454 \mathrm{~A}$ specific adapter, a barcode (red) used to identify a particular sample (also termed the Multiplex Identifier or MID), and a forward primer complementary to a $16 \mathrm{~S}$ rDNA region. At the opposite end of the fragment, there is a $454 \mathrm{~B}$ adapter, a barcode, and a reverse primer complementary to a separate region of $16 \mathrm{~S}$ rDNA. $\mathbf{b}$ The small subunit of

a single bead per well); (8) emulsion PCR (emPCR) creates clonal amplification of ssDNA on each bead; (9) DNA-positive beads are recovered from the microreactors and a bead is loaded along with packing beads and the reaction enzymes into a well of the fiber-optic chip (Pico Titer ${ }^{\mathrm{TM}}$ Plate); (10) the Pico Titer ${ }^{\mathrm{TM}}$ Plate is centrifuged and placed in the sequencer; (11) adenine, cytosine, guanine, or thymidine are separately added and flow over plates during sequencing, and (12) a record of nucleotide incorporation into a DNA strand is based on light emission (i.e. pyrosequencing) and a graphic image is generated (fig. 3). Quality control measures optimize pyrosequencing, while errors that occur during amplification must be rectified before data analyses [49]. In summary, 454 Life Science analyzers detect incorporation of nucleotides into rDNA using the 'sequencing by synthesis' approach. Since a pyrogram cannot be retained for longterm use, the record is transformed into a computerized format for storage and analysis [50,51].

The 1,542 nucleotides that comprise $16 \mathrm{~S}$ rRNA have conserved and variable regions (fig. 2b). This structure is exploited during pyrosequencing to define phylogenetic classifications in microbial communities [52]. Amplicons bacterial rRNA which has conserved (orange) and hypervariable regions (gray with numbers). The variable regions are the 'fingerprint' for microbial classification. Double-headed arrow lines show variable regions commonly used for microbial classification during next generation sequencing. After a 454 pyrosequencing run, a $97 \%$ or greater similarity of a sequence to a region of bacterial $16 \mathrm{~S}$ rRNA is used customarily to assign an OTU or 'Genus and species'.

should have hypervariable regions (e.g. V1-V3) selected specifically to study a given microbial environment [46, 53-56]. The type of genome analyzer used, and whether the device has short or long read lengths, influences which region or regions of hypervariable $16 \mathrm{~S}$ rRNA that are selected for microbial classification. If only one region (e.g. $\mathrm{V} 4$ ) is selected, then the depth of sequencing (i.e. the total number of reads) may overcome limitations associated with short reads that incompletely interrogate $16 \mathrm{~S}$ rRNA.

\section{Next and 3rd-Generation Instrumentation for Studying a Neonatal Microbiome}

\section{Life Sciences Analyzers}

This system is described above because of its frequent use to describe neonatal microbiomes. It is probable that pyrosequencing will be used for the immediate future to study neonatal habitats.

\section{Illumina/Solexa Systems}

The initial steps used by the Illumina and 454 platforms are similar through the creation of a sequencing 
Fig. 3. The pyrosequencing chemical reaction used by the 454 Life Sciences platform. The neonatal intestinal microbiome has most often been studied using the 454 Life Sciences platform. A series of reactions after nucleotide addition to a DNA strand ends in the production of light. The type and number of nucleotides added to ssDNA are recorded as a pyrogram which is transformed for storage and data analyses.

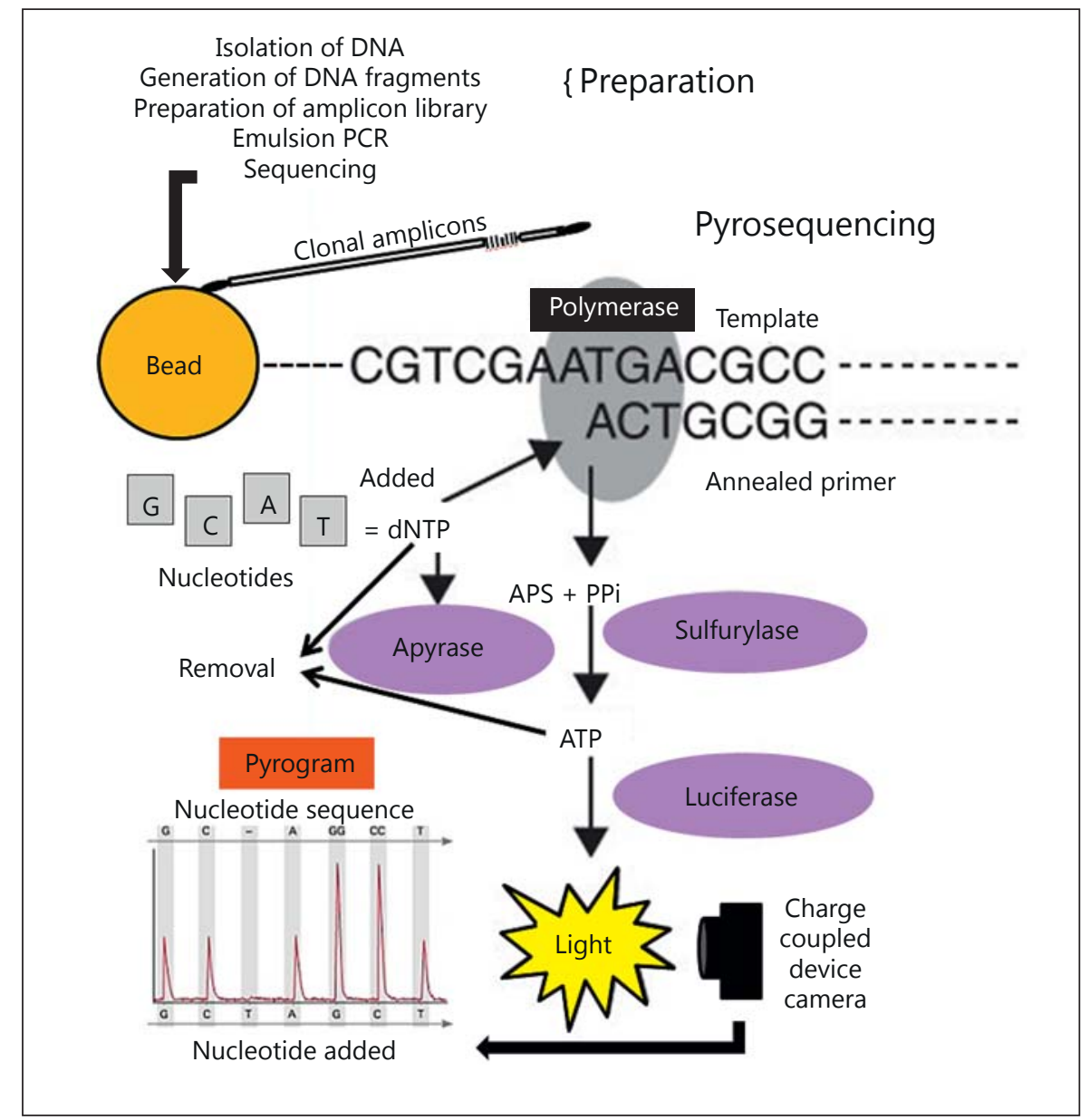

library. Thereafter, the methods are divergent. DNA fragments are attached to a flow cell rather than beads. Bridge amplification is followed by cluster generation, and finally, sequencing primers are annealed to linear DNA amplicons in the clusters (fig. 1b). Sequencing by synthesis occurs after reversible terminator bases and fluorescently labeled nucleotides are added. Non-incorporated nucleotides are washed away, a critical step before imaging because retained, unincorporated fluorescently labeled nucleotides are recorded. Following laser excitation, the emitted fluorescence from each cluster in a flow cell is captured photographically. This results in a large number of reads from the clusters. The accuracy of the Illumina MiSeq platform may decline as read length increases, and depending on the rRNA variable regions used, its shorter reads may hinder microbial classification. Nevertheless, the MiSeq platform is gaining popularity because of lower device and operating costs versus 454 pyrosequencing. A comparison of 454 Life Sciences and Illumina analytical methods to characterize a neonatal microbiome has not taken place. Defining which device performs better should be a future research goal.

\section{Ion Torrent Systems}

This analyzer is a 2.5-generation device because incorporation of nucleotide uses a non-optical method compared to 'light' detection. The platform has a semiconductor that senses release of a proton when a nucleotide is added to a complementary strand of DNA. The purchase cost is lower and the run times are shorter compared to other platforms; however, the raw error rate is higher [57]. This device has been used to study an outbreak of multidrug-resistant Escherichia coli in a neonatal unit [58].

The 3rd-generation platforms are called 'a marriage of nanotechnology with molecular biology'. Two novel devices are briefly described and discussed.
18

Neonatology 2014;105:14-24 DOI: $10.1159 / 000354944$
Sherman/Minnerly/Curtiss/Rangwala/ Kelley 


\section{PacBio RS System}

The protocol creates a DNA library, but there is no amplification step. The device uses a 'single molecule real time' called SMRT ${ }^{\circledR}$ sequencing method. The first innovation uses four specific fluorescent labels that are attached to the terminal phosphate rather than a nucleotide base. During incorporation by a DNA polymerase, the fluorescent label on the nucleotide is cleaved leaving a native DNA strand for incorporation of the next dNTP. The second innovation is the nanophotonic chamber called the Zero Mode Waveguide (ZMW). As a dNTP rapidly flows in and out of the ZMW (a 70-nm cylindrical metallic chamber on a glass support), light is detected as the fluorescent label is excited during nucleotide addition. The rapid incorporation of dNTPs along a single DNA strand results in long reads that are further amplified by multiple ZMV chambers. The device can potentially sequence an entire genome rapidly, but an observed raw error rate of $12.9 \%$ raises concern [57]. This platform was used to analyze the Haitian cholera epidemic [59], but it has not studied neonatal microbiomes.

\section{Oxford Nanopore Technologies}

This platform also does not use DNA amplification. The technology uses either natural, manufactured, or hybrid nanopores with a 1-nm internal diameter that are embedded in an electrically resistant membrane bilayer. There are thousands of nanopores in a membrane. An ionic current passes through the nanopore establishing a voltage across the membrane. Two types of DNA sequencing are utilized: (a) strand sequencing of single nucleotides wherein ssDNA passes through the nanopore [60], and (b) exonuclease sequencing in which single nucleotides are released enzymatically from ssDNA at the nanopore opening and trapped by a beta-dextrin adapter while flowing through the nanopore [61]. A distinctive disruption in current by the biomolecule distinguishes between adenine, cytosine, guanine, and thymidine. Oxford has two analytical systems, the GridION ${ }^{\mathrm{TM}}$ and the miniaturized MinION ${ }^{\mathrm{TM}}$. The platform has a high (4\%) error rate which Oxford says will be reduced to $0.1-1.0 \%$ [62]. Oxford Nanopore devices have not studied neonatal microbiomes.

Issues associated with each genome analyzer, such as read length, error rates in reads, and cost, are becoming evident $[63,64]$. Space limitations required describing analytical devices without visual aids, but we encourage readers to view videos on 'YouTube' which elucidate the mechanisms used by each manufacturer's platform.

\section{Sequencing Analysis and Data Presentation: Defining a Neonatal Microbiome}

Metagenomic analyses are not straightforward. The proper computational tools, training and experience, and collaboration with biostatisticians are required to obtain quality endpoints [51]. The workflow for data analysis has three stages [23]. First, raw data in a storage format are filtered depending on the sequencing platform and the nature of the research. Programs must ascertain read quality (i.e. identify and remove substitutions, insertions, and deletions), detect and eliminate chimeric sequences, assess read length after removing low-quality bases, and remove artifacts [65-67]. Phred and other programs like DRISEE assign a quality score to each base in a sequence [68]; however, the method of acceptance or removal of bases must not be excessively conservative. Chimeras are artificial DNA sequences generated during amplification and can be falsely interpreted as novel bacteria and will inflate the apparent diversity of microbes in a sample. Thus, they must be eliminated. A major concern in 454 pyrosequencing is the correct determination of homopolymers from flow values [69]. 'Noise flow values', defined as light signals that are weak and unrelated to base addition, need removal (see public program: http://blog. malde.org/index.php/flowsim/).

The filtered reads are used in the second step that generates taxonomy and related microbial abundance information by comparison to $16 \mathrm{~S}$ rRNA sequence databases or by using a computer program that reads operational taxonomy units (OTUs). OTUs take the place of 'Genus and species' in analyses of microbiomes. Named 'Genus and species' present in genomes may not match these exact marker sequences. Mothur [70], Greengenes [71] and other software programs facilitate in depth (i.e. Genus and species) OTU-related assignments and are being improved constantly. The assignment of sequences to OTUs is referred to as binning, and acceptance of the assignment from a $16 \mathrm{~S}$ rRNA database often requires sequence similarity levels of 97 or $99 \%$ [72].

The third step is creation of qualitative or quantitative representations of community-related microbes. Different phylogenetic tree formats (e.g. jackknife node graphics) or principal components analytical plots show bacterial populations within or across environments [73, 74]. The abundance of OTUs is often depicted using heat maps, histograms, and pie charts (fig. $4 a-c)$. Descriptive tools used to characterize a microbiome are often derived from the field of ecology [75-78]. These measures of bacterial populations in a habitat include rarefaction curves 
Relative Abundance

(\% of Total Sequences)

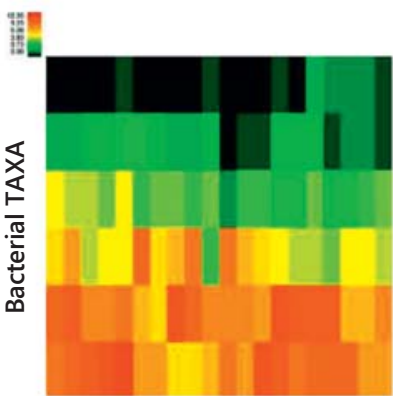

a

Subject Identification


of Sample Richness

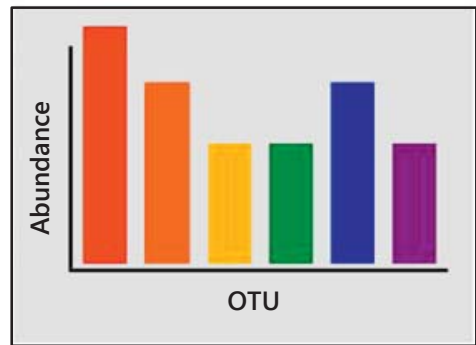

b

HISTOGRAM





C

PIE CHART



Fig. 4. Presentation of next generation sequencing results. a A heat map that examines the proportion of bacterial taxa in individuals; a color key defines the percentage of specific OTUs to an individual's total microbiome. b A histogram identifies different OTUs on the $\mathrm{x}$-axis and abundance of a specific OTU is quantified on the $y$-axis. c A pie chart has a color-coded key to the bacterial taxa present in an environmental sample and the size of the slice corresponds to a percentage of taxa present in the total microbiome. The black slice represents unknown bacteria whose sequence similarity was less than $97 \%$ compared to known sequences in a $16 \mathrm{~S}$ rRNA database. d-f Illustrations of biodiversity in environmental samples from three different subjects. The rarefaction curve (d) is an ecologic assessment tool; the technique assesses species richness in environmental specimens [78]. A steep slope without a plateau means only a fraction of species have been discovered to date, while a flattened curve indicates reasonable sampling and that addition- al interrogation of the habitat will yield only few species. Another ecologic tool is the Shannon Index (e). This statistical calculation measures alpha-diversity which is a reflection of the numbers of species in an environment and their relative abundances, often designated richness and evenness, respectively. Beta-diversity $(\mathbf{f})$ is a comparison of the amount of species change between ecosystems or environments (e.g. oropharynx vs. intestine). Beta-diversity is influenced by the turnover of species in those habitats. Beta-diversity distance matrices can be computed and principal components analytical plots can be generated; a simple form of that illustration is shown (f). QIIME creates rarefaction curves and graphic displays of alpha- and beta-diversity (http://qiime.org/tutorials/tutorial.html). Figures modified and reproduced with author permission: Morgan XC, Huttenhower C: Chapter 12: Human microbiome analysis. PLoS Comput Biol 2012;8:e1002808. and graphic displays of alpha- and beta-diversity (fig. $4 \mathrm{~d}-$ f). QIIME and UniFrac, respectively [79, 80], are online software programs used frequently after pyrosequencing to distinguish bacterial communities in clinical samples. QIIME generates jackknife estimators of abundance data and two- or three-dimensional principal components analytical plots (e.g. showing clusters of OTUs that are similar in an individual or a habitat). These illustrations often appear in publications that study a clinical microbiome.
Examples of graphic displays produced by QIIME are present in a report of bacteria found in neonatal intensive care units [9]. UniFrac-related graphics have been used to report distortions in the gut-related microbiota rather than emergence of pathogens before the onset of late-onset sepsis in hospitalized neonates [81]. Software programs used in analyses of microbiomes can be found at the HMP website (http://hmpdacc.org/tools_protocols/ tools_protocols.php). 
Finally, 16S rRNA-based classification of bacteria does not indicate whether a microbe is viable and capable of either invasion or creation of metabolic effects in the host. By annotating the microbial analysis with information about the metatranscriptome, metaproteome, and metabolome in the habitat, one gains insight into activities of living microbiota. But, such analyses create significant computational challenges $[50,82]$. That topic alone would require a review that surpasses the magnitude of this one.

\section{Conclusions}

The metadata created during analyses of an environmental microbiome results in visual formats that are unfamiliar to most clinicians. This review will hopefully assist neonatal caregivers to decipher current and future studies involving microbiomes. Metagenomics will continue to enhance our understanding of how late-onset neonatal sepsis and necrotizing enterocolitis occur, but large gaps in our knowledge still remain. For example, the virome is absent in the intestine at birth, but thereafter this organ acquires bacteriophages rapidly. Bacteriophages probably have a vital role in gut-related bacterial colonization, the emergence of virulence in intestinal bacteria, and even the prevention or therapy of enteric infections [83-85]. By sequentially studying the emerging microbiome in different neonatal organs and by appreciating the functional changes induced in infants by their resident microbiota [86], researchers can utilize metagenomics to advance neonatal health care.

\section{Acknowledgments}

This work was supported by Gerber Foundation grant PN0021214-2708 and NIH grant HD057744 to M.P. Sherman and an Alfred P. Sloan Foundation award to S.T. Kelley.

\section{Disclosure Statement}

M.P. Sherman, J. Minnerly, W. Curtiss, S. Rangwala and S.T. Kelley have no financial or other conflicts of interest to disclose.

\section{Appendix: Glossary}

$16 S$ rRNA: The smaller subunit component of the prokaryotic ribosome and used as the most common taxonomic marker for microbial communities.
Adapter: A short oligonucleotide of known sequence that is typically attached to longer nucleic acids. In next generation sequencing, an adapter provides a priming site for both amplification and sequencing of the adjoining, unknown nucleic acid.

Amplicons: Segments of DNA that are products of natural or artificial amplification.

Binning: Clustering sequences based on their nucleotide composition or similarity to a reference database; used to make an assignment to a bacterial classification system.

Biodiversity: This is an ecologic measure of the complexity of a community. Alpha-diversity is the number (richness) and distribution (evenness) of taxa expected within a single population. Beta-diversity measures absolute or relative overlap of how many taxa are shared between populations. High biodiversity occurs when many taxa (high richness) are present at similar abundances (an even distribution).

Bridge Amplification and Clustering: Pre-sequencing fragments are immobilized on a flow cell via hybridization involving two adapters attached at opposing ends of the fragment and slide-anchored primers with a sequence complementary to the adapters. Using standard PCR reagents, thermal cycling in the 'primer lawn' produces many copies of the original fragment which localize in a tight cluster. This technology is used in Illumina genome analyzers.

Emulsion Polymerase Chain Reaction (emPCR): A method used for bead-based amplification of a library. A single adapter-bound fragment is attached to a bead and emulsified in oil containing amplification reagents; they surround a bead/fragment. Parallel amplification of single-strand fragments on millions of beads produces many amplicons for a sequencer-ready library. This method is used in 454 Life Sciences and Ion Torrent genome analyzers.

Jackknife Estimator: Jackknife node trees are depictions that estimate the uncertainty in PCoA plots and hierarchical clustering of microbial communities. The concepts are relevant to beta-diversity of habitats. Graphic displays are an output of QIIME software.

Microbiome: The total microbial community and its biomolecules within a defined environment.

Microbiota: The total collection of microbial organisms within a community, typically used in reference to an animal host.

Multiplexing: Pooling of multiple adapter-barcoded libraries into one sequencing run.

Operational Taxonomic Unit (OTU): This is a terminal node designation in phylogenetic analysis of microbiota. OTU is akin to 'Genus and species' in classic microbiology and typically uses rDNA and a percent similarity threshold for classifying microbes.

Principal Coordinates Analysis (PCoA): PCoA is a multidimensional scaling method to explore and to visualize similarities or dissimilarities of data, such as OTUs within in an environment. In two- or three-dimensional plots, the matrix distances of data can be displayed. This graphic analysis is supported by QIIME software.

Pyrosequencing: A method of DNA sequencing detects the release of pyrophosphate upon nucleotide incorporation. This is the chemistry used in 454 Life Sciences genome analyzers.

QIIME (Quantitative Insights into Microbial Ecology): Public software that processes data from high-throughput 16S rRNA sequencing studies. The purpose is to provide a start-to-finish workflow that starts with multiplexed sequence reads and finishes with taxonomic and phylogenetic profiles and comparisons either in a sample or among specimens (i.e. environments). 
Rarefaction Curve: A plot in which the horizontal axis represents samples (often DNA sequences) and the vertical axis represents diversity (e.g. number of distinct taxa).

Read: The primary output of DNA sequencing, consisting of a short stretch of DNA that is defined from sequencing as a region of a single DNA fragment.

Taxonomy: Hierarchical classification of life into three domains, namely eukaryotes, bacteria and Archaea. Metagenomics deals mainly with the classification of bacteria, but can include the viruses and eukaryotic microbes. The bacteria are placed in the largest to smallest groupings starting with Phylum, Class, Order, Family, Genus, and species, respectively.
UniFrac: A method developed to calculate a distance measure between microbial communities using phylogenetic information. A weighted version of the UniFrac metric assigns relative abundance of each of the taxa within the communities. Data is appropriately 'binned' into operational taxonomic units which can then be dealt with as taxa within the UniFrac framework.

Virome: The genomes of all the viruses that inhabit a particular organism or environment.

\section{References}

1 Ursell LK, Clemente JC, Rideout JR, Gevers D, Caporaso JG, Knight R: The interpersonal and intrapersonal diversity of human-associated microbiota in key body sites. J Allergy Clin Immunol 2012;129:1204-1208.

$\checkmark 2$ Madan JC, Salari RC, Saxena D, Davidson L, O’Toole GA, Moore JH, Sogin ML, Foster JA, Edwards WH, Palumbo P, Hibberd PL: Gut microbial colonisation in premature neonates predicts neonatal sepsis. Arch Dis Child Fetal Neonatal Ed 2012;97:F456-F462.

3 Mai V, Young CM, Ukhanova M, Wang X, Sun Y, Casella G, Theriaque D, Li N, Sharma R, Hudak M, Neu J: Fecal microbiota in premature infants prior to necrotizing enterocolitis. PLoS One 2011;6:e20647.

4 Hooper LV, Gordon JI: Commensal host-bacterial relationships in the gut. Science 2001; 292:1115-1118.

5 Palmer C, Bik EM, DiGiulio DB, Relman DA, Brown PO: Development of the human infant intestinal microbiota. PLoS Biol 2007;5:e177.

6 Dominguez-Bello MG, Costello EK, Contreras M, Magris M, Hidalgo G, Fierer N, Knight $\mathrm{R}$ : Delivery mode shapes the acquisition and structure of the initial microbiota across multiple body habitats in newborns. Proc Natl Acad Sci USA 2010;107:11971-11975.

7 LaTuga MS, Ellis JC, Cotton CM, Goldberg RN, Wynn JL, Jackson RB, Seed PC: Beyond bacteria: a study of the enteric microbial consortium in extremely low birth weight infants. PLoS One 2011;6:e27858.

-8 Eggesbø M, Moen B, Peddada S, Baird D, Rugtveit J, Midtvedt T, Bushel PR, Sekelja M, Rudi K: Development of gut microbiota in infants not exposed to medical interventions. APMIS 2011;119:17-35.

9 Hewitt KM, Mannino FL, Gonzalez A, Chase JH, Caporaso JG, Knight R, Kelley ST: Bacterial diversity in two neonatal intensive care units (NICUs). PLoS One 2013;8:e54703.

-10 Tanaka S, Kobayashi T, Songjinda P, Tateyama A, Tsubouchi M, Kiyohara C, Shirakawa T, Sonomoto K, Nakayama J: Influence of antibiotic exposure in the early postnatal period on the development of intestinal microbiota. FEMS Immunol Med Microbiol 2009;56:80-87.
11 Dethlefsen L, Relman DA: Incomplete recovery and individualized responses of the human distal gut microbiota to repeated antibiotic perturbation. Proc Natl Acad Sci USA 2011;108(suppl 1):4554-4561.

12 Morowitz MJ, Carlisle EM, Alverdy JC: Contributions of intestinal bacteria to nutrition and metabolism in the critically ill. Surg Clin North Am 2011;91:771-785.

13 Jacquot A, Neveu D, Aujoulat F, Mercier G, Marchandin H, Jumas-Bilak E, Picaud JC: Dynamics and clinical evolution of bacterial gut microflora in extremely premature patients. J Pediatr 2011;158:390-396.

14 Sherman MP: New concepts of microbial translocation in the neonatal intestine: mechanisms and prevention. Clin Perinatol 2010; 37:565-579.

15 Schwartz S, Friedberg I, Ivanov IV, Davidson LA, Goldsby JS, Dahl DB, Herman D, Wang M, Donovan SM, Chapkin RS: A metagenomic study of diet-dependent interaction between gut microbiota and host in infants reveals differences in immune response. Genome Biol 2012;13:r32.

16 Sherman MP: Lactoferrin and necrotizing enterocolitis. Clin Perinatol 2013;40:79-91.

17 Sherman MP: Intestinal microbes and obesity: a reality check. Commentary on F.B. Morel et al: Can antibiotic treatment in preweaning rats alter body composition in adulthood? (Neonatology 2013;103:182-189). Neonatology 2013;103:190-192.

18 Trasande L, Blustein J, Liu M, Corwin E, Cox LM, Blaser MJ: Infant antibiotic exposures and early-life body mass. Int J Obes (Lond) 2013;37:16-23.

-19 Brown CT, Davis-Richardson AG, Giongo A, Gano KA, Crabb DB, Mukherjee N, Casella G, Drew JC, Ilonen J, Knip M, Hyöty H, Veijola R, Simell T, Simell O, Neu J, Wasserfall CH, Schatz D, Atkinson MA, Triplett EW: Gut microbiome metagenomics analysis suggests a functional model for the development of autoimmunity for type 1 diabetes. PLoS One 2011;6:e25792.
20 Vaarala O: Is the origin of type 1 diabetes in the gut? Immunol Cell Biol 2012;90:271-276.

21 Russell SL, Gold MJ, Hartmann M, Willing BP, Thorson L, Wlodarska M, Gill N, Blanchet MR, Mohn WW, McNagny KM, Finlay BB: Early life antibiotic-driven changes in microbiota enhance susceptibility to allergic asthma. EMBO Rep 2012;13:440-447.

22 Isolauri E: Development of healthy gut microbiota early in life. J Paediatr Child Health 2012;48(suppl 3):1-6.

23 Weinstock GM: Genomic approaches to studying the human microbiota. Nature 2012; 489:250-256.

24 Cabellos-Ruiz A, Janca H, Baena S, Venegas I, Zambrano MM: Beyond metagenomics: integration of complementary approaches for the study of microbial communities; in Marco D (ed): Metagenomics: Theory, Methods, and Applications. Norfolk, Caister Academic Press, 2010, pp 15-37.

25 Blevins SM, Bronze MS: Robert Koch and the 'golden age' of bacteriology. Int J Infect Dis 2010;14:e744-e751.

26 Dunne WM Jr, Pinckard JK, Hooper LV: Clinical microbiology in the year 2025. J Clin Microbiol 2002;40:3889-3893.

27 Woese CR, Fox GE: Phylogenetic structure of the prokaryotic domain: the primary kingdoms. Proc Natl Acad Sci USA 1977;74:50885090.

28 Woese CR, Kandler O, Wheelis ML: Towards a natural system of organisms: proposal for the domains Archaea, Bacteria, and Eucarya. Proc Natl Acad Sci USA 1990;87:4576-4579.

29 Pace NR, Stahl DA, Lane DJ, Olsen GJ: The analysis of natural microbial populations by ribosomal RNA sequences. Am Soc Microbiol News 1985;51:4-12.

30 Schmidt TM, DeLong EF, Pace NR: Analysis of a marine picoplankton community by $16 \mathrm{~S}$ rRNA gene cloning and sequencing. J Bacteriol 1991;173:4371-4378.

- 31 Handelsman J, Rondon MR, Brady SF, Clardy J, Goodman RM: Molecular biological access to the chemistry of unknown soil microbes: a new frontier for natural products. Chem Biol 1998;5:R245-R249. 
-32 Tyson GW, Chapman J, Hugenholtz P, Allen EE, Ram RJ, Richardson PM, Solovyev VV, Rubin EM, Rokhsar DS, Banfield JF: Community structure and metabolism through reconstruction of microbial genomes from the environment. Nature 2004;428:37-43.

-33 Venter JC, Remington K, Heidelberg JF, Halpern AL, Rusch D, Eisen JA, Wu D, Paulsen I, Nelson KE, Nelson W, Fouts DE, Levy S, Knap AH, Lomas MW, Nealson K, White O, Peterson J, Hoffman J, Parsons R, Baden-Tillson H, Pfannkoch C, Rogers YH, Smith HO: Environmental genome shotgun sequencing of the Sargasso Sea. Science 2004;304:66-74.

34 Gilbert W, Maxam A: The nucleotide sequence of the lac operator. Proc Natl Acad Sci USA 1973;70:3581-3584.

- 35 Sanger F, Donelson JE, Coulson AR, Kössel $H$, Fischer D: Use of DNA polymerase I primed by a synthetic oligonucleotide to determine a nucleotide sequence in phage $\mathrm{fl}$ DNA. Proc Natl Acad Sci USA 1973;70:12091213.

- 36 Sanger F, Nicklen S, Coulson AR: DNA sequencing with chain-terminating inhibitors. Proc Natl Acad Sci USA 1977;74:5463-5467.

-37 Mullis KB, Faloona FA: Specific synthesis of DNA in vitro via a polymerase-catalyzed chain reaction. Methods Enzymol 1987;155: 335-350.

- 38 Ronaghi M, Karamohamed S, Pettersson B, Uhlen M, Nyren P: Real-time DNA sequencing using detection of pyrophosphate release. Anal Biochem 1996;242:84-89.

-39 Ronaghi M: Pyrosequencing sheds light on DNA sequencing. Genome Res 2001;11:3-11.

-40 Margulies M, Egholm M, Altman WE, Attiya S, Bader JS, Bemben LA, Berka J, Braverman MS, Chen YJ, Chen Z, Dewell SB, Du L, Fierro JM, Gomes XV, Godwin BC, He W, Helgesen S, Ho CH, Irzyk GP, Jando SC, Alenquer ML, Jarvie TP, Jirage KB, Kim JB, Knight JR, Lanza JR, Leamon JH, Lefkowitz SM, Lei M, Li J, Lohman KL, Lu H, Makhijani VB, McDade KE, McKenna MP, Myers EW, Nickerson E, Nobile JR, Plant R, Puc BP, Ronan MT, Roth GT, Sarkis GJ, Simons JF, Simpson JW, Srinivasan M, Tartaro KR, Tomasz A, Vogt KA, Volkmer GA, Wang SH, Wang Y, Weiner MP, Yu P, Begley RF, Rothberg JM: Genome sequencing in microfabricated high-density picolitre reactors. Nature 2005;437:376-380.

-41 Lederberg J, McCray AT: 'Ome sweet' omics - a genealogical treasury of words. Scientist 2001;15:8.

$\checkmark 42$ Relman DA, Falkow S: The meaning and impact of the human genome sequence for microbiology. Trends Microbiol 2001;9:206-208.

-43 Turnbaugh PJ, Ley RE, Hamady M, FraserLiggett CM, Knight R, Gordon JI: The Human Microbiome Project. Nature 2007;449:804810.

-44 Lauber CL, Zhou N, Gordon JI, Knight R, Fierer $\mathrm{N}$ : Effect of storage conditions on the assessment of bacterial community structure in soil and human-associated samples. FEMS Microbiol Lett 2010;307:80-86.
5 Cardona S, Eck A, Cassellas M, Gallart M, Alastrue C, Dore J, Azpiroz F, Roca J, Guarner F, Manichanh C: Storage conditions of intestinal microbiota matter in metagenomic analysis. BMC Microbiol 2012;12:158.

-46 Wu GD, Lewis JD, Hoffmann C, Chen YY, Knight R, Bittinger K, Hwang J, Chen J, Berkowsky R, Nessel L, Li H, Bushman FD: Sampling and pyrosequencing methods for characterizing bacterial communities in the human gut using $16 \mathrm{~S}$ sequence tags. BMC Microbiol 2010;10:206.

47 Knierim E, Lucke B, Schwarz JM, Schuelke M, Seelow D: Systematic comparison of three methods for fragmentation of long-range PCR products for next generation sequencing. PLoS One 2011;6:e28240.

48 Tamaki H, Wright CL, Li X, Lin Q, Hwang C, Wang S, Thimmapuram J, Kamagata Y, Liu WT: Analysis of $16 \mathrm{~S}$ rRNA amplicon sequencing options on the Roche/454 next-generation titanium sequencing platform. PLoS One 2011;6:e25263.

49 Gilles A, Meglécz E, Pech N, Ferreira S, Malausa T, Martin JF: Accuracy and quality assessment of 454 GS-FLX Titanium pyrosequencing. BMC Genomics 2011;12:245.

50 Angiuoli SV, White JR, Matalka M, White O, Fricke WF: Resources and costs for microbial sequence analysis evaluated using virtual machines and cloud computing. PLoS One 2011; 6:e26624.

51 Thomas T, Gilbert J, Meyer F: Metagenomics - a guide from sampling to data analysis. Microb Inform Exp 2012;2:3.

52 Petrosino JF, Highlander S, Luna RA, Gibbs RA, Versalovic J: Metagenomic pyrosequencing and microbial identification. Clin Chem 2009;55:856-866.

53 Chakravorty S, Helb D, Burday M, Connell N, Alland D: A detailed analysis of $16 \mathrm{~S}$ ribosomal RNA gene segments for the diagnosis of pathogenic bacteria. J Microbiol Methods 2007;69:330-339.

54 Liu Z, Lozupone C, Hamady M, Bushman FD, Knight R: Short pyrosequencing reads suffice for accurate microbial community analysis. Nucleic Acids Res 2007;35:e120.

55 Luna RA, Fasciano LR, Jones SC, Boyanton BL Jr, Ton TT, Versalovic J: DNA pyrosequencing-based bacterial pathogen identification in a pediatric hospital setting. J Clin Microbiol 2007;45:2985-2992.

- 56 Andersson AF, Lindberg M, Jakobsson H, Bäckhed F, Nyrén P, Engstrand L: Comparative analysis of human gut microbiota by barcoded pyrosequencing. PLoS One 2008; 3:e2836.

57 Quail MA, Smith M, Coupland P, Otto TD, Harris SR, Connor TR, Bertoni A, Swerdlow $\mathrm{HP}, \mathrm{Gu}$ Y: A tale of three next generation sequencing platforms: comparison of Ion Torrent, Pacific Biosciences and Illumina MiSeq sequencers. BMC Genomics 2012;13:341.

58 Sherry NL, Porter JL, Seemann T, Watkins A, Stinear TP, Howden BP: Outbreak investigation using high-throughput genome sequenc- ing within a diagnostic microbiology laboratory. J Clin Microbiol 2013;51:1396-1401.

59 Chin CS, Sorenson J, Harris JB, Robins WP Charles RC, Jean-Charles RR, Bullard J, Webster DR, Kasarskis A, Peluso P, Paxinos EE, Yamaichi Y, Calderwood SB, Mekalanos JJ, Schadt EE, Waldor MK: The origin of the Haitian cholera outbreak strain. N Engl J Med 2011;364:33-42.

60 Hammerstein AF, Jayasinghe L, Bayley H: Subunit dimers of alpha-hemolysin expand the engineering toolbox for protein nanopores. J Biol Chem 2011;286:14324-14334.

61 Wu HC, Astier Y, Maglia G, Mikhailova E, Bayley H: Protein nanopores with covalently attached molecular adapters. J Am Chem Soc 2007;129:16142-16148.

62 Hayden EC: Nanopore genome sequencer makes its debut. http://www.nature.com/ news/nanopore-genome-sequencer-makesits-debut-1.10051.

63 Suzuki S, Ono N, Furusawa C, Ying BW, Yomo T: Comparison of sequence reads obtained from three next-generation sequencing platforms. PLoS One 2011;6:e19534.

-64 Loman NJ, Misra RV, Dallman TJ, Constantinidou C, Gharbia SE, Wain J, Pallen MJ: Performance comparison of benchtop highthroughput sequencing platforms. Nat Biotechnol 2012;30:434-439.

65 Schloss PD, Gevers D, Westcott SL: Reducing the effects of PCR amplification and sequencing artifacts on $16 \mathrm{~S}$ rRNA-based studies. PLoS One 2011;6:e27310.

-66 Edgar RC, Haas BJ, Clemente JC, Quince C, Knight R: UCHIME improves sensitivity and speed of chimera detection. Bioinformatics 2011;27:2194-2200.

-67 Jumpstart Consortium Human Microbiome Project Data Generation Working Group: Evaluation of $16 \mathrm{~S}$ rDNA-based community profiling for human microbiome research. PLoS One 2012;7:e39315.

68 Keegan KP, Trimble WL, Wilkening J, Wilke A, Harrison T, D'Souza M, Meyer F: A platform-independent method for detecting errors in metagenomic sequencing data: DRISEE. PLoS Comput Biol 2012;8:e1002541.

-69 Balzer S, Malde K, Lanzén A, Sharma A, Jonassen I: Characteristics of 454 pyrosequencing data - enabling realistic simulation with flowsim. Bioinformatics 2010;26:i420-i425.

-70 Schloss PD, Westcott SL, Ryabin T, Hall JR, Hartmann M, Hollister EB, Lesniewski RA, Oakley BB, Parks DH, Robinson CJ, Sahl JW, Stres B, Thallinger GG, Van Horn DJ, Weber CF: Introducing mothur: open-source, platform-independent, community-supported software for describing and comparing microbial communities. Appl Environ Microbiol 2009;75:7537-7541.

71 McDonald D, Price MN, Goodrich J, Nawrocki EP, DeSantis TZ, Probst A, Andersen GL, Knight R, Hugenholtz P: An improved Greengenes taxonomy with explicit ranks for ecological and evolutionary analyses of bacteria and archaea. ISME J 2012;6:610-618. 
72 Schloss PD, Westcott SL: Assessing and improving methods used in operational taxonomic unit-based approaches for 16S rRNA gene sequence analysis. Appl Environ Microbiol 2011;77:3219-3226.

73 Wooley JC, Godzik A, Friedberg I: A primer on metagenomics. PLoS Comput Biol 2010; 6:e1000667.

-74 Kembel SW, Eisen JA, Pollard KS, Green JL: The phylogenetic diversity of metagenomes. PLoS One 2011;6:e23214.

75 Hughes JB, Hellmann JJ, Ricketts TH, Bohannan BJ: Counting the uncountable: statistical approaches to estimating microbial diversity. Appl Environ Microbiol 2001;67: 4399-4406.

76 Hill TC, Walsh KA, Harris JA, Moffett BF: Using ecological diversity measures with bacterial communities. FEMS Microbiol Ecol 2003;43:1-11.
77 Schloss PD: The effects of alignment quality, distance calculation method, sequence filtering, and region on the analysis of $16 \mathrm{~S}$ rRNA gene-based studies. PLoS Comput Biol 2010; 6:e1000844.

78 Gotelli NJ, Colwell RK: Estimating species richness; in Magurran AE, McGill BJ (eds): Biological Diversity, Frontiers in Measurement and Assessment. New York, Oxford University Press, 2010, pp 39-54.

79 Kuczynski J, Stombaugh J, Walters WA, González A, Caporaso JG, Knight R: Using QIIME to analyze 16S rRNA gene sequences from microbial communities. Curr Protoc Microbiol 2012; Chapter 1:Unit 1E.5.

80 Hamady M, Lozupone C, Knight R: Fast UniFrac: facilitating high-throughput phylogenetic analyses of microbial communities including analysis of pyrosequencing and PhyloChip data. ISME J 2010;4:17-27.

81 Mai V, Torrazza RM, Ukhanova M, Wang X, Sun Y, Li N, Shuster J, Sharma R, Hudak ML, Neu J: Distortions in development of intestinal microbiota associated with late-onset sepsis in preterm infants. PLoS One 2013; 8:e52876.
82 Human Microbiome Project Consortium: A framework for human microbiome research. Nature 2012;486:215-221.

83 Duerkop BA, Clements CV, Rollins D, Rodrigues JL, Hooper LV: A composite bacteriophage alters colonization by an intestinal commensal bacterium. Proc Natl Acad Sci USA 2012;109:17621-17626.

84 Reyes A, Semenkovich NP, Whiteson K, Rohwer F, Gordon JI: Going viral: next-generation sequencing applied to phage populations in the human gut. Nat Rev Microbiol 2012;10:607-617.

85 Fortier LC, Sekulovic O: Importance of prophages to evolution and virulence of bacterial pathogens. Virulence 2013;4:5,1-12.

86 Zarraonaindia I, Smith DP, Gilbert JA: Beyond the genome: community-level analysis of the microbial world. Biol Philos 2013;28: 261-282. 